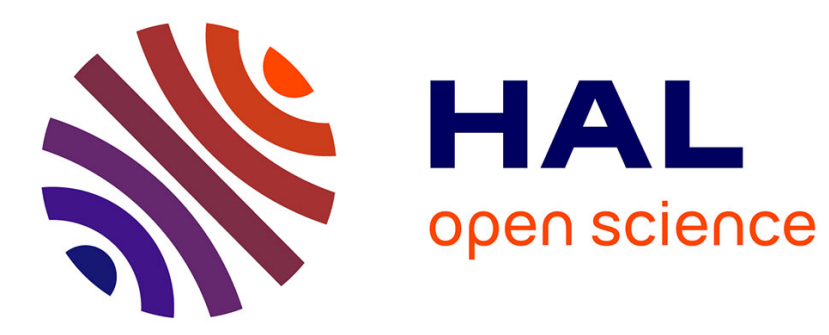

\title{
Wave steadiness in aluminas
}

N. Bourne, Z. Rosenberg, John Field, I. Crouch

\section{To cite this version:}

N. Bourne, Z. Rosenberg, John Field, I. Crouch. Wave steadiness in aluminas. Journal de Physique

IV Proceedings, 1994, 04 (C8), pp.C8-269-C8-274. 10.1051/jp4:1994840 . jpa-00253395

\section{HAL Id: jpa-00253395 https://hal.science/jpa-00253395}

Submitted on 1 Jan 1994

HAL is a multi-disciplinary open access archive for the deposit and dissemination of scientific research documents, whether they are published or not. The documents may come from teaching and research institutions in France or abroad, or from public or private research centers.
L'archive ouverte pluridisciplinaire HAL, est destinée au dépôt et à la diffusion de documents scientifiques de niveau recherche, publiés ou non, émanant des établissements d'enseignement et de recherche français ou étrangers, des laboratoires publics ou privés. 


\title{
Wave steadiness in aluminas
}

\author{
N.K. Bourne, Z. Rosenberg*, J.E. Field and I.G. Crouch** \\ Shock Physics, PCS, Cavendish Labs., Madingley Road, Cambridge CB3 OHE, U.K. \\ * RAFAEL, P.O. Box 2250, Haifa, Israel \\ ** DRA, Chobham Lane, Chertsey, Surrey KTI6 OEE, U.K.
}

\begin{abstract}
Plate impact experiments have been carried out on two aluminas of differing grain size using the Cambridge $50 \mathrm{~mm}$ gas gun. Tiles were constructed in thicknesses of 4,8 and $12 \mathrm{~mm}$ and were impacted by $3 \mathrm{~mm}$ thick copper projectiles fired at $550 \mathrm{~m} \mathrm{~s}^{-1}$. The longitudinal stress in the tiles was recorded using manganin stress gauges and a $1 \mathrm{GS} \mathrm{s}^{-1}$ storage oscilloscope. Measurements were made of the elastic precursor of the deformation wave in each of these experiments. It was found that the elastic precursor varied significantly with thickness and that different behaviours were shown by the large and small grain size materials
\end{abstract}

\section{INTRODUCTION}

The dynamic response of ceramic materials to impact results from an interest in their possible use as armour materials or as engine turbine blades. The early literature ([1]-[5]) showed ceramic materials to exhibit very high dynamic compressive strengths (HELs). Munson and Lawrence [6] used the velocity interferometry system for any reflector (VISAR) to obtain accurate figures for the HEL and generated renewed interest in ceramics in impact situations. Further studies have extended the range of materials characterised, a review of which appears in Rosenberg [7]. Techniques for numerical evaluation of the stress-strain behaviour of ceramics have been developed by several authors including Kipp and Grady [8].

In materials of the type studied below the HEL for a ceramic is believed to provide a threshold below which the material retains some cohesion and has finite spall strength and above which the material has zero spall strength and becomes an inertially confined powder [9]. However, Longy and Cagnoux [10] have reported examples of alumina recovered at twice HEL with cracks not interconnected. This work and that due to Clifton et al. [11] suggested that shear strain energy was dissipated in the material principally by twinning and dislocation motion in the alumina grains whereas our work inferred intergranular microcracking to be the dominant mechanism.

It is a well documented property of metals that the elastic precursor assumes an initially elevated value for very thin samples which decays to an asymptote after the wave has run some distance through the target (eg. the studies in iron by Taylor and Rice [12]). This phenomenon has been dubbed elastic precursor decay. The data of Gust and Royce [3] show that a similar effect exists in ceramics although they do not 
comment on this in their paper. Work performed in [13] shows indications of decay for alumina specimens. This work aims to further confirm that this effect exists in aluminas and relate the decay characteristics to the microstructure by measurements of the elastic wave of the deformation wave on tiles of thickness 4-12 mm impacted under closely identical conditions.

\section{MATERIALS}

The Deranox aluminas 3 and 4 were produced as $25 \mathrm{~mm}$ thick, $150 \mathrm{~mm}$ square tiles by isostatic pressing as experimental variants upon a commercial production grade material. Following firing these were then cut and lapped into the sample size of 4,8 and $12 \mathrm{~mm}$ thick, $50 \mathrm{~mm}$ squares. Values for density and sound speed were measured to an accuracy of $0.1 \%$. Materials data are summarised in tables 1 and 2 . Sample 3 was fired at $1580^{\circ} \mathrm{C}$ whilst 4 was fired at a higher temperature of $1700^{\circ} \mathrm{C}$ in an attempt to encourage grain growth.

Grain size was determined by image processing of scanning electron micrographs of the sample surface. The area and the maximum and minimum dimensions of each grain were measured and the figures were reduced to an average equivalent diameter assuming the grain was spherical. Grain size distributions for various materials can be found in [14]. Samples of $c a .100$ grains were used for the measurements.

TABLE 1 COMPOSITION OF ALUMINAS (WT \%)

\begin{tabular}{|c|c|c|c|}
\hline Oxide & $\begin{array}{c}\text { Assumed } \\
\text { density }\left(\mathrm{g} \mathrm{cm}^{-3}\right)\end{array}$ & $\begin{array}{c}\text { Deranox } \\
3\end{array}$ & $\begin{array}{c}\text { Deranox } \\
4\end{array}$ \\
\hline $\mathrm{Al}_{2} \mathrm{O}_{3}$ & 3.97 & 97.4 & 96.3 \\
\hline $\mathrm{SiO}_{2}$ & 2.32 & 1.54 & 2.15 \\
\hline $\mathrm{CaO}$ & 3.32 & 0.34 & 0.43 \\
\hline $\mathrm{MgO}$ & 3.58 & 0.76 & 0.39 \\
\hline $\mathrm{TiO}_{2}$ & 4.26 & 0.01 & 0.01 \\
\hline $\mathrm{Fe}_{2} \mathrm{O}_{3}$ & 5.24 & 0.02 & 0.03 \\
\hline $\mathrm{K}_{2} \mathrm{O}$ & 2.32 & 0.02 & 0.06 \\
\hline $\mathrm{Na}_{2} \mathrm{O}$ & 2.27 & 0.04 & 0.05 \\
\hline $\mathrm{Mn}_{3} \mathrm{O}_{4}$ & 4.86 & $\mathrm{NK}$ & $\mathrm{NK}^{*}$ \\
\hline Theoretical density $\left(\mathrm{g} \mathrm{cm}^{-3}\right)$ & 3.928 & 3.906 \\
\hline
\end{tabular}

*NK not known.

TABLE 2 MATERIAL PROPERTIES

\begin{tabular}{|l|c|c|}
\hline DERANOX GRADES & 3 & 4 \\
\hline $\mathrm{Al}_{2} \mathrm{O}_{3}(\%)$ & 97.4 & 96.3 \\
\hline Glass Content & 2.6 & 3.7 \\
\hline \hline Theoretical Density $\left(\mathrm{g} \mathrm{cm}^{-3}\right)$ & 3.93 & 3.91 \\
\hline Measured Density $\left(\mathrm{g} \mathrm{cm}^{-3}\right)$ & 3.79 & 3.76 \\
\hline Calculated porosity $(\%)$ & 3.6 & 3.8 \\
\hline \hline Hardness (Rockwell R45N) & 85 & 80 \\
\hline Toughness (MPa $\sqrt{\mathrm{m}})$ & 3.83 & 3.91 \\
\hline Firing Temperature $\left({ }^{\circ} \mathrm{C}\right)$ & 1580 & 1700 \\
\hline Mean Gn. Size $(\mu \mathrm{m})$ & 4 & 8 \\
\hline Stnd. Deviation. $(\mu \mathrm{m})$ & 2 & 6 \\
\hline Longitudinal Sound Speed $\left(\mathrm{km} \mathrm{s}^{-1}\right)$ & 10.27 & 10.15 \\
\hline
\end{tabular}

The closed porosity was determined by comparing measured and theoretical densities and the method of calculation is indicated in the tables.

\section{EXPERIMENTAL}

The results presented were collected from instrumented plate-impact experiments carried out on the singlestage gas gun at the Cavendish laboratory $\left(50 \mathrm{~mm}\right.$ bore, $1 \mathrm{~km} \mathrm{~s}^{-1}$ maximum impact velocity). Uniaxial strain compressive shock and rease waves were recorded after travel through 4,8 and $12 \mathrm{~mm}$ thick tiles of alumina backed with $12 \mathrm{~mm}$ thick PMMA blocks. The longitudinal stress normal to the planar wave fronts was recorded using piezoresistive stress gauges embedded $1 \mathrm{~mm}$ away from the ceramic/PMMA interface in the backing block. 


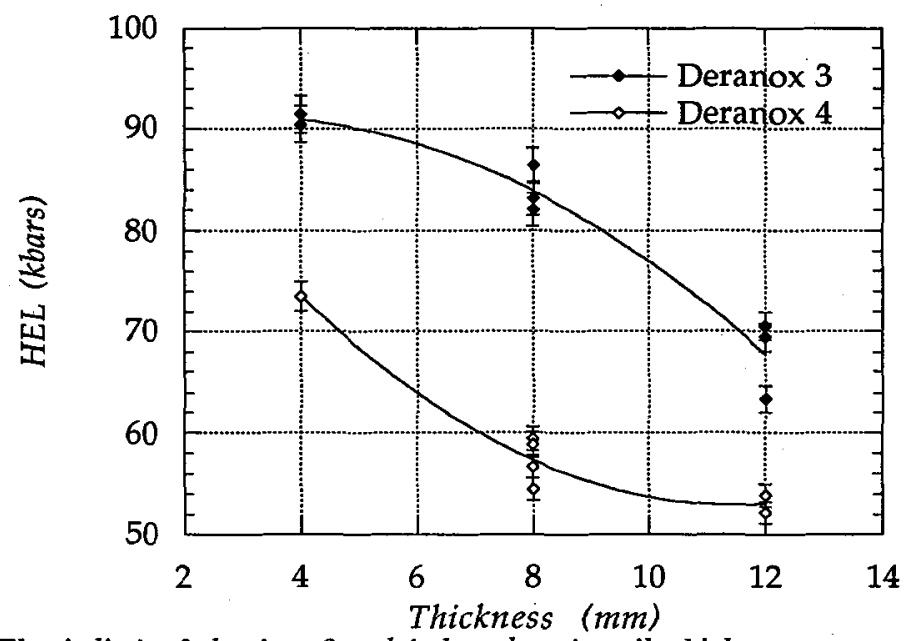

Figure 2. Elastic limit of aluminas 3 and 4 plotted against tile thickness.

Several such signals were gathered for each tile thickness with the impactor material and velocity kept the same in each case. The resulting elastic limits were determined and reduced to in material values using the transmission coefficient (1) above. The total error on each measurement arising from the gauge calibration and the determination of the elastic limit from the trace was estimated to be $\pm 2 \%$. The resulting data are plotted against thickness in figure 2.

The following features can be recognised.

(i) There is a clear trend of decreasing elastic limit with thickness. The values for alumina 3 are above those for 4.

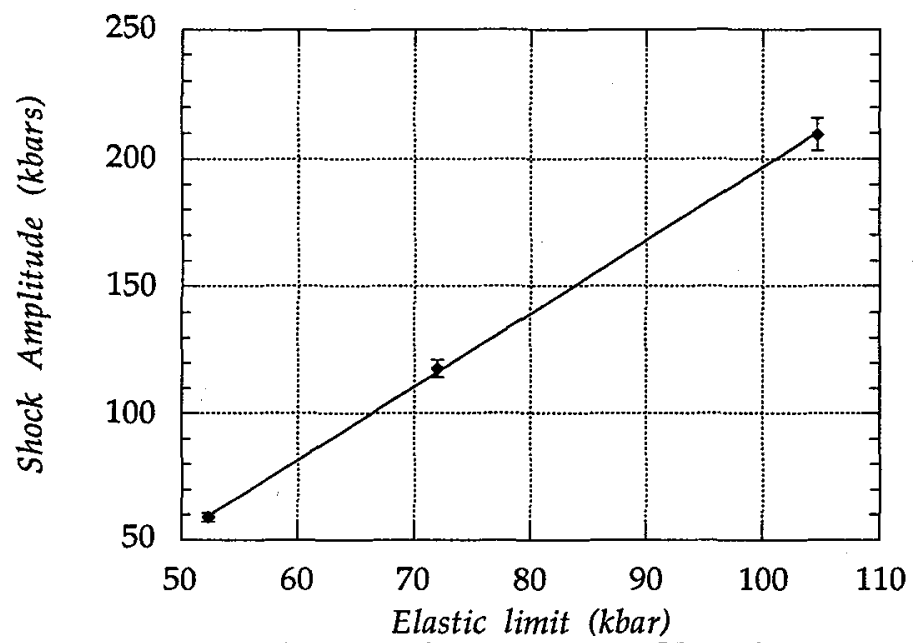

Figure $3 \quad$ Impacts on $4 \mathrm{~mm}$ thick tiles of alumina 4 at 338,558 and $863 \mathrm{~m} \mathrm{~s}^{-1}$. The measured elastic limit varies with the shock amplitude.

(ii) The error on each measurement is less than the spread in the measured values of the elastic limits that results from the statistical strength properties of the ceramic. 
The PMMA backing was chosen because it acoustically matches both the gauge's backing material and the epoxy used to assemble the sample. The signal recorded thus followed the form of the stress history accurately and with minimal smoothing of discontinuous stress rises (signal rise times of $\mathrm{ca}$. $30 \mathrm{~ns}$ were typical on elastic waves).

The gauges used were MicroMeasurements manganin gauges (LM-SS-125CH-048) and the calibration data of Rosenberg et al. [15] were used in reducing the voltage data collected. The signals were recorded using a fast (1GS s$s^{-1}$ ) digital storage oscilloscope and transferred onto a micro-computer for data reduction. Impact velocity was measured to an accuracy of $0.5 \%$ using a sequential pin-shorting method and tilt was adjusted to be less than $1 \mathrm{mrad}$ by means of an adjustable specimen mount. Impactor plates were made from lapped copper and aluminium discs and were mounted onto a polycarbonate sabot with a relieved front surface in order that the rear of the flyer plate remained unconfined.

Since data were collected in PMMA a correction for the amplitude transmission across the ceramic/PMMA interface using acoustic impedances was applied assuming a Hugoniot for PMMA determined experimentally [16]. A novel feature of the gauge mounting was that the gauge was positioned $1 \mathrm{~mm}$ from the ceramic/PMMA interface into the PMMA. This reduces electrical effects produced during impact.

\section{RESULTS}

Each of the traces presented here consisted of $c a .3000$ recorded points. For ease of presentation only 150 points are used to represent each record. Since the gauge measures the transmitted stress wave amplitude in PMMA a correction must be made for the transmission coefficient $(T)$ from alumina to PMMA. This can be expressed in terms of the acoustic impedances $\left(Z_{1}, Z_{2}\right)$ of the two materials as

$$
T=\frac{2 Z_{1}}{Z_{1}+Z_{2}} \text {. }
$$

In the subsequent figures the stress recorded within the PMMA backing is presented and correction to inmaterial values is noted separately using the value for $T$ calculated from measured values of density and longitudinal wave-speed.

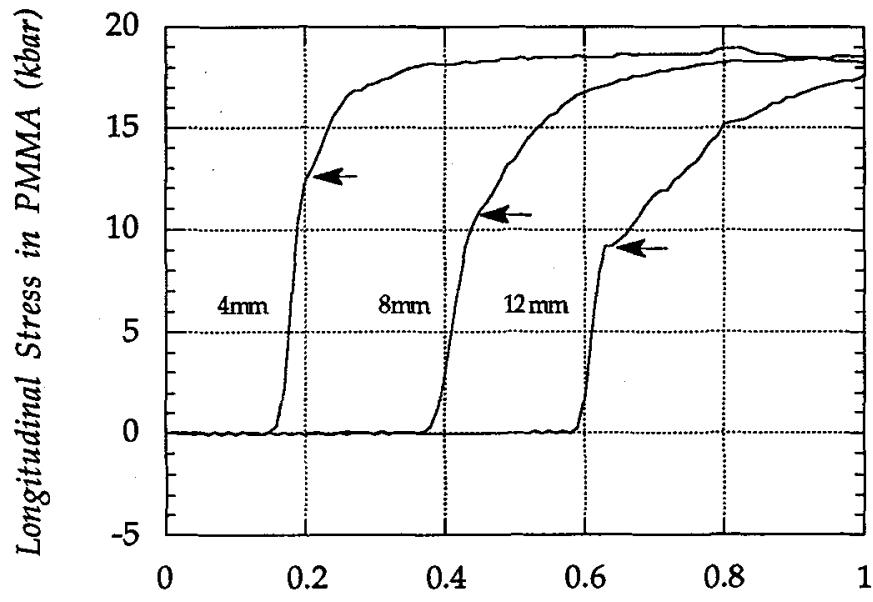

Time ( $\mu s$ )

Figure 1 Impacts on alumina 4. Velocity $550 \pm 8 \mathrm{~ms}$-1. Gauge placed back into sample by $1 \mathrm{~mm}$ PMMA. The elastic rises of each of the pulses can be seen with the break in slope at the elastic limit indicated by an arrow.

Figure 1 shows typical waveforms for three impacts at $550 \pm 9 \mathrm{~m} \mathrm{~s}^{-1}$. The elastic limit is arrowed for each tile thickness. The precursor decay is immediately obvious from the figure. 
(iii) The form of the decrease is different between the two aluminas.

Further experiments were carried out on $4 \mathrm{~mm}$ tiles of alumina 4 . The results are presented in figure 3 . The elastic limit was measured at differing impact velocities. It was noted that the measured value for higher shock amplitudes was greater than that measured at lower amplitudes. This was an indication of the non-steadiness of the wave at $4 \mathrm{~mm}$ thickness.

\section{DISCUSSION AND CONCLUSIONS}

The results of figure 2 show that the ratio of the measured elastic limits is close to that expected by assuming a Hall-Petch relation between the strength and the grain size. The data for alumina 4 resemble the data in [14] in that the elastic limit appears to have reached an asymptotic value at $12 \mathrm{~mm}$. The general shape of the best fit line is as expected from precursor decay in metals. However, alumina 3 shows opposite curvature and such a trend can be seen in the work of Gust and Royce [3] for $\mathrm{B}_{4} \mathrm{C}$. We believe that the different curvatures shown in figure 2 are due to the differing glass contents of the two aluminas. It is also plausible that the differences in composition of the glasses resulting from different additives also has an influence on the differing curvatures. More work has to be done in order to resolve this issue.

The data points for alumina 4 at $8 \mathrm{~mm}$ can be considered as a scatter in the elastic limit indicative of the statistical nature of the material properties for these ceramics. Such results have been noted for other aluminas tested. In this case for alumina 4 the elastic limit is $57 \pm 3$ kbars.

Two more indications of the non-steady nature of the wave can be seen in figures 1 and 3 . The first concerns the rise time of the deformation wave which increases appreciably with the thickness of the specimen. The second is the increase of the elastic limit with the amplitude of the final shock. Both these features were closely related in metals to the decrease of the elastic precursor with distance (see [12]). The observed features in the failure of these brittle materials should be explained by a complete failure model as is the case in metals e.g. Taylor and Rice [12].

\section{ACKNOWLEDGEMENTS}

This work was carried out with the support of DRA. DRA Chertsey are acknowledged for provision of samples. Dr W.A.J. Carson of DRA Chertsey and Dr I.G. Cullis of DRA Fort Halstead are thanked for their encouragement and support.

\section{REFERENCES}

[1] Ahrens T.J., Gust W.H., and Royce E.B. (1968) J. Appl. Phys. 39, 4610-4616.

[2] Graham R.A., and Brooks W.P. (1971) J. Phys. Chem. Solids 32, 2311-2330.

[3] Gust W.H., and Royce E.B. (1971) J. App. Phys. 42, 276-294.

[4] Gust W.H., and Royce E.B. (1972) J. App. Phys. 43, 4437-4442.

[5] Gust W.H., Holt A.C., and Royce E.B. (1973) J. App. Phys. 44(2), 550-559.

[6] Munson D.E., and Lawrence R.J., (1979) J. Appl. Phys. 50, 6272-6282.

[7] Rosenberg Z., (1992) in APS proceedings of Shock Waves in Condensed Matter 1991, eds. Schmidt S.C., Dick R.D., Forbes J.W., Tasker D.G., Elsevier Publishers B.V., 439-446.

[8] Kipp M.E., and Grady D.E., (1990) in APS proceedings of Shock Waves in Condensed Matter 1989 eds. Schmidt S.C., Johnson J.N., and Davison L.W., Elsevier Publishers B.V., 377-380.

[9] Bourne N.K., Rosenberg Z., Crouch I.G., Field J.E., (1994) Proc. R. Soc. Lond. A, In press.

[10] Longy F., and Cagnoux J., (1990) in APS proceedings of Shock Waves in Condensed Matter 1989 eds. Schmidt S.C., Johnson J.N., and Davison L.W., Elsevier Publishers B.V., 441-444.

[11] Clifton R.J., Raiser G., Ortiz M., and Espinosa H., (1990) in APS proceedings of Shock Waves in Condensed Matter 1989 eds. Schmidt S.C., Johnson J.N., and Davison L.W., Elsevier Publishers B.V., 437-440.

[12] Taylor J.W. and Rice M.H., (1963) J. Appl. Phys, 34, 364-371.

[13] Rosenberg Z., Brar N.S., Bless S.J., (1988) J. De Physique 49, Colloq. C3, 707-711.

[14] Bourne N.K., Field J.E., Rosenberg Z., Statham P., (1993) Cavendish Laboratory Report prepared under contract EMR 2029/268, March.

[15] Rosenberg Z, Yaziv, D., and Partom Y. (1980) J. Appl. Phys. 51(7), 3702-3705.

[16] Bourne N.K., (1994) Cavendish Laboratory Report prepared under contract EMR 2029/268, January. 
Brar N.S., Rosenberg Z., Bless S.J., (1992) in APS proceedings of Shock Waves in Condensed Matter 1991, eds. Schmidt S.C., Dick R.D., Forbes J.W., Tasker D.G., Elsevier Publishers B.V., 467470.

Gilman J.J., (1992) in APS proceedings of Shock Waves in Condensed Matter 1991, eds. Schmidt S.C., Dick R.D., Forbes J.W., Tasker D.G., Elsevier Publishers B.V., 387-390.

Grady D., (1992) " in APS proceedings of Shock Waves in Condensed Matter 1991, eds. Schmidt S.C., Dick R.D., Forbes J.W., Tasker D.G., Elsevier Publishers B.V., 455-458.

Rosenberg Z., (1993) J. Appl. Phys. 74(1), 752-753. 